\title{
The Need to Address Psychological and Neurological Characteristics of Learners in the Mainstream Education System
}

\author{
Chandana Watagodakumbura \\ School of Electrical and Computer Engineering, RMIT University \\ PO Box 2476, Melbourne, Vic, 3001, Australia \\ Tel: +61 399252092 E-mail: chandana.watagodakumbura@rmit.edu.au
}

Received: Dec. 3, 2013 Accepted: December 19, 2013 Published: February 1, 2014

doi:10.5296/jse.v4i1.4662ＵRL: http://dx.doi.org/10.5296/jse.v4i1.4662

\begin{abstract}
Individual learners can be characterised based on their psychological and neurological characteristics, such as visual spatial and auditory sequential learners, extroverts and introverts or multiple intelligences. These differences go a long way in how successfully individuals learn and engage in their careers. However, our contemporary educations systems do not give due attention to these differences in satisfying individual requirements. For example, the issues related to high sensitivities of gifted and creative individuals being inadequately addressed in the mainstream education system are extensively highlighted in literature. Due to lack of support from the education and social systems, individuals fall behind in the process of self-actualisation. According to researchers, it appears that we focus mainly on instructing the learners' left hemisphere of the brain, paying little attention on the right hemisphere. In this paper, the author highlights the need to make learners use both hemispheres of the brain through appropriate instructions and methodologies, despite some having preferences to using one half. Addressing psychological and neurological needs of the learners while accommodating them to use both brain hemispheres would put individuals into a self-actualising path that develops creativity and wisdom. In essence, as general educators, we develop awareness into the concept of neurodiversity.
\end{abstract}

Keywords: Neurodiversity, Psychological and neurological characteristics, Gifted individuals, Self-Actualisation, Creativity and wisdom 


\section{Introduction}

Our contemporary education systems primarily follow a one-type-fits-all approach to teaching-learning. This is despite wealth of research findings available on significant individual learner differences (Armstrong, 2011; Eide \& Eide, 2006; Silverman, 2002). Among these differences, the psychological and neurological ones are too important to be neglected. Especially, those who are categorised as gifted and creative individuals are at the receiving end when the above differences are neglected in the mainstream education system (Moyle , 2005; Silverman, 2002; Webb, 2008).There are a number of classifications used over the years for characterising individuals psychologically and neurologically. The famous psychologists Abraham Maslow and Kazimierz Dabrowski presented a number of research outputs in this regard (Dabrowski, 1970; Maslow, 1968, 1993). However, these differences are not taken into account in general in the main stream education system. We argue that this is a significant limitation of our contemporary education systems, among other similar deficiencies suggested by a number of other philosophers and educators (Houston, 1999, 2004; Marchese, 2012; Smyre, 2006; Sylwester, 1998, 2001; Watagodakumbura, 2012, 2013b). Even though addressing these individual differences goes beyond the boundary of the discipline of pedagogy, it is unavoidable if we are to pursue a deeper perspective to education that leads to a more sustainable social development. In this paper, we emphasise the above need of supporting individual psychological and neurological differences within the mainstream education system by presenting and integrating the available supporting literature in a unified manner.

\section{Categorisation of Individuals: Learning Styles and Personality Types}

There are a number of classifications available to categorise individuals based on their personality types or learning styles. Some commonly used preference contrasts are introversion and extroversion, feeling and thinking and intuition and sensing. It is important to note that they are considered as preferences; that is, even though a single individual may have a preference in one type he or she may possess some degree of inclination to the opposite type as well.

\subsection{Myers-Briggs Type Indicator}

Myers-Briggs Type Indicator (MBTI) is a psychometric assessment commonly used to identify individual preferences, especially when one seeks or change employment. In fact, it has been used for many decades now. The MBTI responses can be used to either select the ideal candidate for a specific employment or to accommodate an already selected candidate with appropriate environmental needs. The MBTI assessment includes all the opposite preference pairs mentioned in the previous section and additionally the pair of judging and perceiving.

\subsection{Multiple Intelligences}

In another classification, Howard Gardner initially identified seven main types of intelligences, so to speak, that we can use to characterise individual strengths: linguistic, spatial, logical-mathematical, musical, bodily-kinesthetic, intrapersonal and interpersonal 
(Gardner, 2006). Later, he added naturalistic and existential intelligences to the list. Intrapersonal intelligence may indicate one's ability to develop self-awareness, while interpersonal intelligence may relate to how an individual deals with fellow members of the society; for example, we may assume that a highly empathic individual has good interpersonal intelligence. Empathy is an emotion that is prominent in highly evolved individuals and involves the functions of many parts of the brain, as identified by Kazimierz Dabrowski (Battaglia, 2002). Intrapersonal intelligence has a special value in ideal education as it helps individuals to self-identify themselves based on their individual characteristics. Self-identification can then lead to better interpersonal relationships, as individuals will be able to understand other members of the society in depth as well, similar to identifying oneself deeply. On the whole, improved intrapersonal and interpersonal intelligences help individuals to develop better peer relationships and engage in group work collaboratively. Clearly different multiple intelligences highlight the functions of different parts of the brain; for example linguistic and logical processing involves the left hemisphere while the spatial and musical functioning mainly uses the right hemisphere (Silverman, 2002). In addition logical-mathematical and linguistic intelligences more prominently use the frontal integrative cortex, the spatial and intrapersonal intelligence uses the back integrative cortex, interpersonal and bodily-kinesthetic intelligences use motor cortex while the musical intelligence uses the sensory cortex (Zull, 2002). From the viewpoint of education, the importance of recognising the existence of multiple intelligences, or abilities, is that, even if one does not possess prominent abilities in one, or a few areas, he or she may have better abilities in some other area. Also, a single individual may possess multiple abilities even though some may be more prominently demonstrated. Identification of an individual's stronger abilities helps us to encourage and motivate him or her in those areas while, at the same time, concentrating on the improvement of the others. Further, by recognising that there are multiple functional areas involving different parts of the human brain, we can systematically pursue developing individuals holistically.

\subsection{Auditory Sequential and Visual Spatial Learning Styles}

Another categorisation psychologists have come up with is to differentiate learning styles of individuals as auditory sequential learning and visual spatial learning (Silverman, 2002; Webb, 2005). The simplicity of this classification lies with the fact that it has only two broad categories. As implied by the terms used, auditory sequential learners prefer auditory inputs and sequential instructions and visual spatial learners, on the other hand, prefer visual and spatial information. As an example, a learner with high visual spatial abilities may not enjoy learning purely listening to a speaker who provides sequential instructions; he or she may prefer to look at map to get to a destination instead of following auditory instructions. The most significant fact in this classification is that it aligns well, or clearly differentiates, with which part of the brain each group prefers to process information. That is, left hemisphere of the brain is more specialised in processing linguistic and sequential information while right hemisphere is better in dealing with visual and spatial information. In other words, learners with the preference of auditory sequential style predominantly use the left hemisphere while the learners with the visual spatial preference mostly use the right hemisphere. Research 
studies indicate that two thirds of population possess primarily auditory sequential characteristics while the other one third has predominantly visual spatial characteristics. We do not refer here to an ON-OFF type strict categorisation of strictly one type or other; rather it is a continuous scale where an individual may fall into any position, demonstrating a bias into a single category ahead of the other. In relation to these learning styles, psychologists have also identified other associated psychological, neurological and personality characteristics. The students with preference to the auditory sequential learning style are more inclined to have extrovert personalities while the students with preference to the visual spatial learning style are inclined to possess introvert personalities. Extrovert personalities are more outgoing, engage in discussions and respond easily, even with relatively unknown people, and enjoy social activities large number of participants. In contrary, introverts prefer attending to things on their own with less interaction with others, especially with relatively unknown people, and dislike social activities with large attendance. Auditory sequential learners good in analysis and pay more attention to detail; they approach solving a complex problem by dividing it in to smaller parts. On the other hand, visual spatial learners are good synthesisers who can relate different perspectives to form an answer and better at seeing the big picture or are holistic. As we would expect, auditory sequential learners deals better with concept of time and are better organised while visual spatial learners relatively less competent with the concept of time. Auditory sequential learners think in words and are better in rote memorisation; visual spatial learners think in pictures and need to relate contextual meanings with pictures, and as a result struggle with rote memorisation. That is, auditory sequential learners have better auditory short-term memory while visual spatial learners have better visual long-term memory. Further, since they think in pictures, visual spatial learners take relatively longer time to process and relate information to contexts, once they do that this contextual information is retained longer in memory. In traditional educational environments, as the main instructional medium is audition, auditory sequential learners automatically become the consistent high achievers while visual spatial learners may struggle in those environment and achievements become very inconsistent, despite very high abilities in visual spatial spectrum. Auditory sequential learners are able to engage in learning despite emotional setbacks while learning of visual spatial learners is heavily dependent on emotional stability. This implies that visual spatial learners are more sensitive, or overexcitable, individuals. In relation to mathematical abilities, visual spatial learners are better in mathematical reasoning, while auditory sequential learners are good in arithmetic. In terms of the thinking style, auditory sequential learners are more convergent thinkers while the visual spatial learners are divergent thinkers, suggesting possibly possessing imaginational overexcitability. Researchers have observed that visual special learners have tendency to be categorised as gifted and creative individuals who usually show a very high level of emotional and other sensitivities. The learner categorisation in to auditory sequential and visual spatial learning styles has the significance that it uses a more intrinsic psychological and neurological basis, or biological underpinning, than other extrinsic measures. Contemporary societies or the ones existed before do not necessarily encourage or reward creativity, morality or empathic behaviours. 


\section{Maslow's Conceptualisations}

\subsection{Maslow's Theory of Self-Actualisation}

The famous psychologist Abraham Maslow referred to personnel with high development potential as self-actualising individuals; at the highest level of human development, these individuals become highly creative and self-actualised human beings who become aware of and accept reality as it is, facing it boldly with much less complaining (Maslow, 1968). Self-actualisation is a hierarchical process of fulfilling individual developmental needs; at the lowest level we have the fulfilment of basic needs such as food and shelter; above that we have the feeling of security through employment and other means; further up we have the needs of love, respect and belonging from family and society, before reaching the highest level of self-actualisation with higher level of autonomy. It is important to understand that above needs at each level are necessary requirements but not essentially sufficient ones; that is, fulfilling the needs of a lower level does not necessarily mean that an individual move to a higher level of human development. Moving to a higher level always become a challenge, leaving behind a lower level stability into a relatively new territory, and depends on the personal decisions of the individuals. Self-actualisation is an idiosyncratic process as every individual is different from the others. That is each individual will have to embark on the process to self-actualisation in an individualised manner. Importantly, Maslow also identified high sensitivity, especially emotional sensitivity, in self-actualising individuals. Self-actualisers also have high moral sensitivity and develop contended states of mind overall. As discussed earlier, gifted and creative individuals are the more sensitive members of the society and have the potential to be in an accelerated process to self-actualisation. Maslow further pointed out that most of the human beings do not reach higher levels of development, or self-actualisation, that are inherent to human nature, due to lack of conducive social and educational environments (Maslow, 1993); Maslow stressed on point that for human beings to self-actualise, it is essential that we have good social conditions, that is, a society that promotes and values human development. He referred to societies that negatively contribute the self-actualisation process of individuals as "sick societies" as opposed to "healthy societies". We may have to ask the question ourselves here whether we hold back our high potential individuals from self-actualising through our improper social practices; this may conspire against promoting the development of healthy and sustainable societies.

\subsection{Maslow on Education}

Maslow (1993) emphasised on the point that we need to prepare our learners to face the changes that take place rapidly; the social conditions change continuously and individuals essentially need to be prepared for it. His approach was to encourage creativity in leaners and the learning process to be a character training undertaking. Put differently, Maslow put forth that goals of education are human goals; that is humanistic development, or self-actualisation of individuals. To achieve this, he stated that we need to guide our learners through intrinsic motivation for learning that help them to self-identify themselves, or their personalities. Maslow's approach to education especially contrasts from an approach that only focuses on the development narrow set of skills, in a specific employment area. Similar views on 
education are held by the Polish psychologist and psychiatrist Kazimierz Dabrowski as well, as we highlight later.

\subsection{Authentic Education and Maslow's Views}

There is a quite a bit of overlapping in the authentic education system Watagodakumbura (2013a) proposes and views of Maslow. In authentic education, the author emphasises on the significance of human development and characterisation of learners on individual basis. Developing creative human beings mean that we encourage learners to view from multidimensional perspectives; we need them to develop a diverse set of neural networks of knowledge, connecting them appropriately to construct a vast knowledge base. This enhanced deeper knowledge help individuals to become more empathic, contended and self-actualising personnel. This aligns well with the view of Socrates as quoted by Maslow (1993) "no man with full knowledge could ever do evil". Thus, the self-actualisation process will have a physical meaning, indicating the growth of neural networks of knowledge.

\section{Special Education Programs for Gifted Individuals}

Psychologists working with gifted children and adults promote special education programs for gifted individuals as the traditional education environments create a negative impact on those individuals and their development. There is a myriad of research findings to support this fact and we only have to evaluate whether special education programs are the only or best option available to support a significantly large cohort of our learners. Contrary to this, there are other powerful groups that do not see the need of special programs for the most capable learner group, disregarding any of their vulnerabilities, including high sensitivities, or overexcitabilities, whatsoever. We can infer that individuals with preference to auditory sequential learning style are more likely to cope positively in a traditional educational environment than the group of visual spatial learners that constitute a high proportion of gifted learners. With the term traditional educational environment, we mean what we have been doing generally for over hundreds of years in education. A person knowledgeable in a particular area speaks regularly for a period of time in front of, usually, a large gathering of students who are later assessed for their competence, typically with a written examination at the end of the study period. The assessments are usually based on the recall of facts as opposed to an individual's ability to evaluate and synthesise, the so called higher-order learning activities. The key feature of this approach is that all the students are expected to engage in an identical manner to the unit, or course, disregarding any diversity within the student cohort as learners. Especially when the class size is large, operationally it becomes very difficult to pay attention on each individual student. From a teaching-learning perspective, we tend to quite dramatically simplify the environment with the assumption that all the students learn in the same way and they all respond to the assessments in the same manner. We usually do not appreciate that students may have different learning styles based on their psychological as well as neurological characteristics, and thus that there would be differences in meeting the assessment requirements. We have enough evidence that some student categories, such as those with preference to visual special learning styles, do not do their best in timed tests and multiple choice question tests, especially if not properly 
constructed (Silverman, 2002). These students are usually better abstract thinkers and the said type of assessment would, in many cases, not test their abilities appropriately. Thus the grades awarded to the students are biased heavily on the methodology followed by the specific teacher who conducted the course (Yero, 2002), and to some extent on the standards and regulations imparted by the governing academic administrative unit, or organisation. The students may have been tested for the ability to merely recall the facts; they may have been tested for application of knowledge; they may have been tested for ability to analyse; they may have been tested for ability to synthesise; they may have been tested for ability to evaluate. But the grades do not differentiate them, or whether the testing was more inclined for higher-order learning or lower-order learning. Averaging results obtained for assessment targeting different positions of higher-order lower-order spectrum will not differentiate the strong and weak abilities of a learner; it will rather nullify those strong and weak attributes and produce a distorted picture. Research psychologists have provided enough evidence to accept that those who are capable of and motivated in recalling facts are not necessarily good in analysing or synthesising information, or vice versa. What we end up under these circumstances is that the authenticity of student learning is greatly challenged and misinterpreted. As a result, we can reasonably justify the call for special education programs for gifted personnel by some insightful advocates, mainly in the medical and psychology disciplines, at least as a first step or in the interim, until some broad changes to our general education is inflicted, if that ever takes place.

\section{Work Type Categorisation: Implementation and Integration Types}

The author would like to view the categorisation of auditory sequential and visual spatial learners from another different perspective as well (Watagodakumbura, 2013a). We see in our environment different types of tasks we, as human beings, perform daily. They can be broadly categorised into tasks of implementation and tasks of integration. The tasks of implementation have to be attended by performing one step at a time and paying attention to detail, more or less in a routine manner, whereas tasks of integration have to be performed with more contemplative and creative manner, possibly taking more time to see the big picture and also to see things from different perspectives. Examples for former type of tasks may include driving a vehicle, building a wall by putting bricks together, playing a game such as cricket, soccer or tennis, cooking a meal, servicing a customer at a counter or restaurant and feeding raw material or items to a machine in a production line. On the other hand, diagnosing a medical condition based on the symptoms, judging whether someone is at fault depending on the evidence available, planning a month long trip to an unknown place, planning visits to a number of places or towns within a day minimising the overall time spent and distance travelled and researching a solution to a perennial problem of professional or personal life are examples for integration type of work. Personnel who find themselves at ease relatively in attending tasks of implementation can be categorised as implementers while those who find intrinsically at ease relatively in attending tasks of integration can be called integrators. As Elaine Aron (1999) put forth, appropriate vocations are important for sensitive individuals to thrive; they are the royal advisors but not the warrior kings. However, if you consider the life of any individual, he or she is most likely to engage in both implementation 
and integration type tasks, irrespective of his or her chosen or engaged career. For example, one may engage in driving as a career, but he or she may have to plan a month long trip to an unknown place or visit many places during a day minimising the time taken and distance travelled from time to time. On the other hand, one may be a medical practitioner by profession diagnosing medical conditions based on symptom, but may have to drive a vehicle or cook his or her meals either regularly or from time to time. Even though these are very basic examples, as a matter of fact, developing both implementer abilities as well as integrator abilities would be useful in any individual's life. If we go through the personality traits of auditory sequential and visual spatial learners carefully, it would not be hard to realise that implementers are more likely to fall into the category of auditory sequential learners while integrators are likely to fall into the category of visual special learners. That is, implementers are more likely to use the left hemisphere predominantly while the integrators are more likely to use the right hemisphere mostly. Further, from another perspective, integrators would use the integrative cortices of the cerebral cortex extensively while implementers may rely mostly on motor and sensory cortices in attending to their preferred tasks. It is worth noting that even though an individual may have a bias towards one type of learning style, he or she may have reasonably well developed skills or abilities in the other learning style. The other possibility would be that an individual is extremely biased towards one learning style and miss the skills and abilities of the other significantly. The important fact is that in our environments we have both categories of tasks, or careers, present and the society can benefit from personnel of more inclined personality traits of integrators as well as implementers. The challenge in the provision of ideal education is to identify these personality traits of individuals accurately, help them more specifically to improve on the weaker traits and guide them to suitable career paths so they find themselves more at ease intrinsically, or naturally, resulting more integrated and happier human minds, thus the society benefiting from more efficient and effective human resources utilisation. In our current practices, we tend to categorise an individual into a career path or disciplinary area at an early stage and continue to develop his or her skills, or abilities, only in that area narrowly, utilising most of the time available to him or her, thus without giving a chance for the individual to develop holistically, or in an all-round manner. As a result, the concept of life-long learning will yield a constrained meaning and value pushing individuals narrowly in a confined career path. Decades ago, Maslow (1993) observed the lack of opportunity available for individuals to develop humanistically, or progress in the self-actualisation process, by stating "human nature has been sold short”. If we look around our environment carefully, we see that the majority of tasks, or careers, we engage in daily are of implementation type and comparatively a smaller percentage is of the type integration. However, we must emphasise here that this fact has a contemporary social context in which the tendency is to push individuals in narrow career paths for prolonged periods of time such as thirty to forty years targeting mainly economic benefits at the expense of holistic human development. Further, this fact of contemporary task type distribution aligns well with the research findings that, in general, two thirds of the personnel are of predominantly auditory sequential type learners while the other one third is of the visual spatial type learners. It is important to understand that there is no hard-line demarcation between auditory sequential 
and visual spatial learning styles, or between implementer and integrator work categories, or between extroverted and introverted personality types. It is that, an individual would possess more personality traits of one type than the other. In other words, it is not a strict two state or ON/OFF type categorisation; rather it can be seen as a continuous scale where an individual may lie anywhere on it. Under these conditions, we can also infer that there is more likelihood that an integrator type personality gets trapped in an implementation type task, or career, resulting a struggle or unhappy work environment for the individual. In contextual jargon, we refer to these scenarios as work-related stress, absence of work-life balance or under more severe conditions, depressions and related mental disorders. This is despite the fact that visual spatial learners or integrator type personalities possessing higher abstract thinking and spatial capabilities.

\section{The Need to Utilise Both Hemispheres of the Brain}

When we consider the two learning styles of auditory sequential and visual spatial, we observe that each style make use of one part of the human brain predominantly than the other parts. That is auditory sequential learners use the left hemisphere predominantly while the visual spatial learners use the right hemisphere (Silverman, 2002). The two hemispheres mainly perform two different functions and all these functions are important for individuals to operate optimally in the society. If we inquire with an open mind, it is not hard to realise that we all have both hemispheres and why would we encourage individuals to only or mostly use one? Or can we make our learners use both hemispheres, even if they have some bias towards using one? In an ideal educational environment, we need to send our learners through activities involving both hemispheres. In this way, we make them realise their full potential. Despite individuals having preferences, our instructions and activities should target getting both hemispheres involved in the learning process, or in decision making. There is research evidence that when human beings get involved in more creative activities, both hemispheres of the brain get activated in functioning. Consequently, it is possible get creative instincts of our learners aroused by using the correct inputs, or instructions. In an authentic educational framework, as a first step, we need to identify different activities we can make use to engage both hemispheres and then use them in our curricular to give our learners a more balanced learning experience. In a traditional learning environment, we predominantly used instructions and assessment to cater our learners' left hemisphere, which has resulted in an unbalanced situation as a whole, while, at the same time, was unfair for another group of learners in a neurodiverse society.

\section{Negative Images and Stereotyping of Gifted and Creative Individuals}

\subsection{Existential Depression}

We do also have significant research findings that visual spatial learners, or gifted learners, as they are highly likely to be categorised, are more likely to develop negative images of themselves as well as of the society at large when their requirements and preferences are not met for a prolonged period of time. The negativity could emerge as a result of study or work related matters or in some cases due to the natural inclination in pondering on some unanswerable philosophical questions such as the meaning of life. Such situations even 
extend to cause them psychological problems, sometimes in the extremes, leading to existential depression or similar conditions in some individuals, during certain stages of their lives (Webb, 2008). Letting them suffer in these conditions can result in significant loss of productivity individually as well as at societal levels and even life threatening in some occasions.

\subsection{Psychoneurotics and Theory of Positive Disintegration (TPD)}

According to research findings, it is also possible that, due to their heightened sensitivity, gifted individuals demonstrate frustrated behaviours at times. Kazimierz Dabrowski in his book "Psychoneuroses Is Not an Illness" (1972) even refers to individuals of these traits as "psychoneurotics" and identified the underlying process of psychoneuroses as a path to higher level of human development. He uses the term "psychoneurotics” to highlight the fact that these individuals have atypical but thoroughly acceptable behaviours that deviate from commonly expected average human behaviours. Insightfully, Dabrowski was full of praise for "psychoneurotics" for their unusual but very useful abilities, while at the same time sympathised with them for not being understood by the society in a positive frame of mind. Dabrowski observed that "psychoneurotics" are more adjusted to "what ought to be", or a higher level of reality, even though they are maladjusted to "what is", or everyday realism. That is, they are capable of conceptualising and transcending to a higher level of reality than the reality we see on everyday basis. It raises the issue that we, as a society, have the tendency to push for conformity, normalcy, or average behaviour, instead of accepting diversity, or more specifically neurodiversity. We come back to the point of justifying the use of special education programs for gifted individuals, especially if the public education system cannot be broadened and the community members cannot be better educated. Dabrowski (1970) has highlighted the phenomenon of psychoneuroses that leads to the Theory of Positive Disintegration (TPD) in which he identified individuals with high developmental potential need to disintegrate from lower levels of development, or psychological status, before re-integrating at higher levels of development. TPD is termed that way as moving to higher levels of human development is in fact something positive even though the process involves some disintegration from lower but stable development, or psychological status. In Dabrowski's theory he identifies five levels of human development, 5 being the level at which humanistically highly evolved individual lie. At the highest level, individuals have highly empathic, creative and autonomous personalities, so to speak, and have achieved a secondary integration, following disintegration from the primary level. Gifted individuals with high overexcitability, or sensitive, characteristics usually have high potential to develop to higher levels, even though this is not an automatic process; that is, despite high developmental potentials, due to lack of environmental and social support, gifted individuals fall short of achieving it. Dabrowski's research findings show that a large portion of our population stay at level 1 , the lowest level of development without moving to the higher developmental stages, a result that was also observed by Maslow in his study of self-actualising individuals. Once one is firmly integrated at the lowest level of development, which is referred to as primary integration, he or she needs a deep shake up, or disintegration process of psychoneuroses, before moving up to a higher level. This shake up process can 
sometimes be critical, according to Dabrowski, as he found through autobiographical studies of individuals, as some end up in suicidal attempts. But Dabrowski highlighted that even personal or other tragedies could result in accelerated development humanistically, causing them to disintegrate from the primary integration level (Battaglia, 2002). Moving to a higher layer from a lower layer essentially involves a disintegration process, or psychoneuroses process. Further, developing as a human being we referred to here is not the same as developing individuals in economic perspectives; it is about developing in to be a more creative, empathic and contended human being even though economic stability, at least to fulfil basic needs, may help on in reaching this status. However, whether or how such human qualities are valued and encouraged in our contemporary society is a different matter for discussion.

\subsection{Misdiagnosis of Gifted Individuals}

Some other, more recent scholars too have raised the issue of misdiagnosing gifted individuals as having disorders or learning disabilities in significant numbers (Webb, 2005; Silverman, 2004; Aron, 1999); these incidents could occur, most probably, due to misjudgement of gifted individuals' highly intense and unusual reactions to some social situations. Most of these misdiagnoses are related to psychological problems or mental illnesses. The behaviour of gifted individuals may not confine to what is typically understood as normal, but the reason for such behaviour could be environmental stimuli. Consequently, if the healthcare and medical professionals do not consider the contextual situation for the behaviour, they may end-up in misdiagnosing gifted individuals, accounted by pathological underpinning. For example, how could one verify whether an individual has attention deficit hyperactive disorder (ADHD) or it is merely a depiction of psychomotor overexcitability? How could we be sure whether an individual suffers from Asperger's disorder or he or she has merely an introverted personality? When sleep deprivation due to social or personal conditions cause lack of attention that leads to hallucinations, are we going to come up with a diagnosis of schizophrenia (Webb, 2005)? The issue the author is trying to highlight here is that whether we can, as educators and parents, identify and address the issues and requirements of these highly sensitive but capable personnel. These personalities are more likely to demonstrate psychological imbalances, or deviate from standard behaviour, compared to the personnel of average personalities. Ideally, the education system needs to address the needs of different personality types in identifying their strengths and fostering them as means of developing authentic personalities. When these authentic personalities are actualised, any mismatch between who they are really and what is common or seen in the environment is minimised. They also learn to be more resilient of any discrepancy that may occur.

\section{The Need to Accept Neurodiversity}

We have seen the significance and one very important feature of any education system. It essentially means that we are giving due recognition for different personality types, based on the broad concept of neurodiversity, and thereby for diverse strengths and learning styles, so that each student maximises the effectiveness of his or her learning experience in accordance 
to his or her personality traits. This is a totally different approach to what we commonly practice now, literally trying to fit one size to all, creating a significant mismatch and discrepancy. Psychologists emphasise on embracing the diversity within the human species as opposed to fitting them all into one hypothetical creature possessing imaginary qualities and features (Armstrong, 2011). The idea of neurodiversity is as if the human species is like a rainforest, even though it is only a single species, consisting of diverse plants and trees, small and large, growing in water and land, giving it its much needed equilibrium with the nature and at the same time causing it to be very attractive to botanists and other interested parties. Every plant or tree contributes positively to the balance sustainability of the rainforest; similarly every neurodiverse human being can contribute positively for the communities, or societies they live if they are fostered appropriately. Higher the humanistic development of each individual toward the unique highest potential level, the better the positive contributions that would be received by the communities.

\section{Paying Attention to the Needs of the Gifted Individuals as General Educators}

There is another significant observation in relation to implementing an ideal education system; we have those professional and practicing psychologists proposing special education programmes for gifted personnel and a separate group of general educationists who strive to make students learn deeply with enhanced understanding as if it is only a matter of adhering to sound pedagogical practices in fulfilling good teaching-learning. This somewhat contradictory situation raises the question whether we need special education programs for gifted individuals only because we as educationist, in general, do not follow sound pedagogical principles, or in other words do we need to broaden our general educational context to cater every individual inclusively. Interestingly, those general educationists who write on sound pedagogical practices rarely raise the issues pertaining to gifted individuals. Consequently, what is essential is that we, as the general educators, need to get our attention focused as to why a special group of psychologists promoting special education programmes for gifted personnel. Is there a significant view-point that we, as the general educators missing out, completely or partially? We, the general educators may need to consider, or at least get directed to give due considerations for different learning styles preferred by different student categories. We may be educators in different disciplines, such as disciplines related to natural sciences, social sciences, liberal arts or technology, so on and so forth; but why is that we usually see that the pedagogical principles are only explicitly practiced and promoted by those who are involved directly in the discipline of pedagogy. It is not uncommon that we, as educators, who are not practicing in the discipline of pedagogy, express ourselves cynically towards some pedagogical principles, let alone considering psychological or neurological traits of individual students. We may argue, we have been doing teaching-learning for hundreds of years and we have achieved so much, even sending rockets to the moon, and why do we need to change, or a different approach? The simplest answer would be, are we doing things perfectly, are we highly proactive and are we fair? Essentially we need to raise and broaden our awareness overcome any limitations, whatever they may be. Further, we may ask ourselves - "Is it merely a learning style that is important", from pedagogical point of view. Even if we address the issues related to learning styles, how can 
we address the issue of different paces of learning demonstrated by individual for various reasons in a commonly set curriculum, completed within a specified period? We need to go beyond these simplistic perceptions of learning styles in understanding more in depth the associated personality traits as done by psychologists and related professionals. This essentially leads to a multi-disciplinary perspective in providing education, or more correctly providing ideal education, or developing authentic personalities - an authentic whole human being. That is, trying to understand and categorise students in accordance to their intrinsic personality traits, as done by some groups of psychologists or neurologists, and matching the learning experiences, followed by career options, to suit them are significant aspects of an ideal educational system. In other words, ideal education, as we referred to here in a deeper context, essentially has a multi-disciplinary perspective.

\section{Conclusion}

Individual psychological and neurological differences are too significant to be neglected in any teaching-learning environment. They play an important role in how well individuals learn and engage in their careers. Facilitating these differences in the teaching-learning environment should not be restricted only to some groups who are supported by some psychological and neurological testing activities. Rather, these facilities should be available in the mainstream education system so that every individual benefits by having individualised learning plans.

\section{References}

Armstrong, T. (2011). The Power of Neurodiversity: Unleashing the Advantages of Your Differently Wired Brain. Da Capo Lifelong Books.

Aron, E. (1999). Highly Sensitive Person: How to Thrive When the World Overwhelms You. New York, NY: Three Rivers Press

Battaglia, M (2002). A Hermeneutic Historical Study of Kazimierz Dabrowski and his Theory of Positive Disintegration. Blacksburg, VA: PhD Thesis at Virginia Polytechnic Institute and State University. Retrieved from http://scholar.lib.vt.edu/theses/available/etd-04082002-204054/unrestricted/Dissertation.pdf.

Dabrowski, K. (with Kawczak A. and Piechowski M. M.). (1970). Mental Growth through Positive Disintegration. London: Gryf Publications

Dabrowski, K. (1972). Psychoneuroses Is Not An Illness. London: Gryf Publications

Eide, B. \& Eide, F. (2006). The Mislabelled Child: How Understanding Your Child's Unique Learning Style Can Open the Door to Success. New York: Hyperion .

Gardner, H. (2006). Multiple Intelligences: New Horizons. New York: Basic Books.

Houston, J. (1999). Vision of the Future. New Horizons for Learning: School of Education, Johns Hopkins University. Retrieved from http://education.jhu.edu/PD/newhorizons/Neurosciences/articles/ 
Houston, J. (2004). Social Artistry. New Horizons for Learning: School of Education, Johns Hopkins University. Retrieved from http://education.jhu.edu/PD/newhorizons/Neurosciences/articles/

Marchese, T. J. (2012) New Conversations about Learning Insights. New Horizons for Learning: School of Education, Johns Hopkins University. Retrieved from http://education.jhu.edu/PD/newhorizons/Neurosciences/articles/

Maslow, A. (1968). Toward a Psychology of Being. New York: Van Nostrand Reinhold.

Maslow, A. (1993). Farther Reaches of Human Nature. New York, N.Y., U.S.A.: Arkana.

Moyle, V. F. (2005). Authentic Character Development - Beyond Nature and Nurture. Supporting Emotional Needs of the Gifted (SENG). Retrieved from http://www.sengifted.org/archives/articles/authentic-character-development-\%E2\%80\%93-be yond-nature-and-nurture.

Silverman, L. K. (2002). Upside-Down Brilliance: The Visual-Spatial Learner, Denver: DeLeon Publishing.

Smyre, R. (2006). On Searching for New Genes: A 21st Century DNA for Higher Education. New Horizons for Learning: School of Education, Johns Hopkins University. Retrieved from http://education.jhu.edu/PD/newhorizons/Neurosciences/articles/

Sylwester, R. (1998). The Downshifting Dilemma: A Commentary and Proposal. New Horizons for Learning: School of Education, Johns Hopkins University. Retrieved from http://education.jhu.edu/PD/newhorizons/Neurosciences/articles/

Sylwester, R. (2001). Unconscious Emotions, Conscious Feelings, and Curricular Challenges. New Horizons for Learning: School of Education, Johns Hopkins University. Retrieved from http://education.jhu.edu/PD/newhorizons/Neurosciences/articles/

Watagodakumbura, C. (2012). Improving Student Learning through Multidisciplinary Perspectives. Journal of Teaching and Education, International Journal of Arts \& Sciences, 1(5), 261-267. Retrieved from http://www.universitypublications.net/jte/index.html

Watagodakumbura, C. (2013a). Authentic education: visualising education in a deeper perspective. World Journal of Education, Sciedu Press, 3(3), 1-10. Retrieved from http://www.sciedu.ca/journal/index.php/wje/article/view/2725

Watagodakumbura, C. (2013b). Subtle but important pedagogical practices yielding authentic learning experience. Proceedings of the Clute Institute International Academic Conference 2013, 346-351. Retrieved from http://www.cluteinstitute.com/proceedings/2013HIPapers/Article\%20326.pdf

Webb, J.T. (with Amend E. R., Webb N.E., Goerss J., Beljan P, and Olenchak F.R.) (2005). Misdiagnosis and Dual Diagnoses of Gifted Children and Adults: ADHD, Bipolar, Ocd, Asperger's, Depression, and Other Disorders. Great Potential Press

Webb, J. T. (2008). Dabrowski’s Theory and Existential Depression in Gifted Children and 


\section{Macrothink}

Journal of Studies in Education

ISSN 2162-6952 2014, Vol. 4, No. 1

Adults. Paper presented at the Eighth International Congress of the Institute for Positive Disintegration in Human Development, August 7-9, Alberta, Canada.

Yero, J. (2002). How Teacher Thinking Shapes Education. New Horizons for Learning: School of Education, Johns Hopkins University. Retrieved from http://education.jhu.edu/PD/newhorizons/Neurosciences/articles/

Zull, J. E. (2002). The Art of Changing the Brain: Enriching the Practice of Teaching by Exploring the Biology of Learning. Stylus Publishing. 